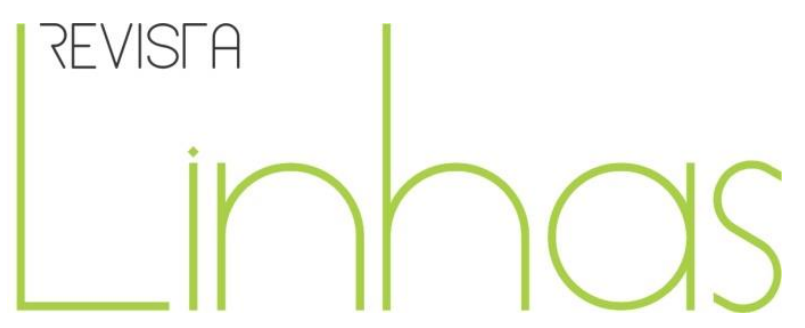

\title{
Acervos escolares e história das instituições educacionais: o caso da Escola Estadual General Osório/RS
}

\begin{abstract}
Resumo
Um dos temas atuais na pesquisa em História da Educação referese aos acervos escolares, por constituírem espaços de preservação da memória e da identidade das instituições educacionais. Destaca-se, ainda, que tais acervos viabilizam o acesso a uma série de fontes de pesquisa para quem se dedicará investigação historiográfica sobre a temática educacional. Para tal fim, iniciou-se em 2012 o mapeamento dos acervos escolares da cidade de Osório-RS. O município conta com quatro escolas em funcionamento há mais de três décadas: Escola Estadual de Ensino Fundamental General Osório; Escola Estadual de Educação Básica Prudente de Moraes; Escola Estadual de Ensino Médio Ildefonso Simões Lopes e Escola Estadual Cônego Pedro Jacobs. Neste mesmo ano, todo o acervo fotográfico da Escola Estadual de Ensino Fundamental General Osório foi digitalizado. Em 2013, deuse continuidade ao projeto iniciado no ano anterior, efetuando-se sua organização e catalogação. A importância de preservar os acervos escolares da cidade de Osório reside notadamente no fato de haverem sido realizados poucos estudos sobre a história da maior parte dessas instituições ou sobre as práticas escolares domunicípio. Deve-se ter em conta, ainda, que tal organização viabilizará o acesso de pesquisadores a esses arquivos.
\end{abstract}

Palavras-chave: Acervos; História das Instituições Educacionais; Fotografias; Documentos.

\author{
Maria Augusta Martiarena de Oliveira \\ Doutora em Educação pela \\ Universidade Federal \\ de Pelotas - UFPEL \\ Professora do Instituto Federal de \\ Educação, Ciência e Tecnologia do Rio \\ Grande do Sul - IFRS \\ martiarena.augusta@gmail.com
}

\section{Para citar este artigo:}

OLIVEIRA, Maria Augusta Martiarena de. Acervos escolares e história das instituições educacionais: o caso da Escola Estadual General Osório/RS. Revista Linhas. Florianópolis, v. 15, n. 28, p. 154-174, jan./jun. 2014.

DOI: 10.5965/1984723815282014154

http://dx.doi.org/10.5965/1984723815282014154 


\title{
School collection and history of educational institutions: the case of General Osório School, Osório/RS
}

\begin{abstract}
One of the current issues in research in History of Education refers to school collections, because they constitute as spaces to preserve the memory and identity of educational institutions. It is important to realize that the school collections provide access to many research sources for those engaged in historiographical research on educational themes. In this sense, we began in 2012 mapping the school archives of the city of Osório - RS. The town has four schools with more than three decades of operation: General Osório, Prudente de Moraes, Ildefonso Simões Lopes and Cônego Pedro Jacobs. In the same year, we had scanning the photographic collection at the General Osório School. In 2013, we still worked with the same project, making up the organization and cataloging of the photographic collection of the institution. It is important to preserve the school archives of the city of Osório because it was a little quantity of studies on the history of most of these institutions or on school practices that municipality were performed. And also, the organization of these collections will enable researchers to access these files.
\end{abstract}

Keywords: Collections; History of educational institutions; Photographs; Documents. 


\section{Introdução}

Um dos temas atuais na pesquisa em História da Educação refere-se aos acervos escolares, por constituírem espaços de preservação da memória e da identidade das instituições educacionais. Ainda, os acervos escolares viabilizam o acesso a uma série de fontes de pesquisa para quem se dedica à investigação historiográfica sobre a temática educacional.

Em 2012 iniciou-se o mapeamento dos acervos escolares da cidade de Osório-RS. O município conta com quatro escolas estaduais de ensino fundamental em funcionamento há mais de três décadas: a General Osório; a Ildefonso Simões Lopes, a Cônego Pedro Jacobs e a Escola Básica Prudente de Moraes. Destaca-se que já existem investigações sobre duas escolas: a Ildefonso Simões Lopes e a Prudente de Moraes. Optou-se, por isso, iniciar ainda neste ano a digitalização do acervo fotográfico da escola General Osório. Em 2013, deu-se continuidade ao projeto iniciado no ano anterior, efetuando-se a organização e catalogação de seu acervo fotográfico.

O presente artigo relata o andamento do projeto de pesquisa empreendido no Instituto Federal de Educação, Ciência e Tecnologia do Rio Grande do Sul - Campus Osório -, com vistas à preservação dos acervos escolares da cidade. Até o presente momento, o acervo dessa escola é a principal fonte de pesquisa, juntamente com os documentos do Arquivo Histórico Antônio Stenzel Filho.

\section{A Escola General Osório e a caracterização de seu acervo}

A Escola Estadual de Ensino Fundamental General Osório é a instituição de ensino mais antiga em funcionamento na cidade de Osório, no estado do Rio Grande do Sul. A trajetória dessa instituição iniciou-se com a fundação da $15 \cdot{ }^{a}$ Escola Mista e com a designação da professora Maria Thereza Villanova de Castilho, pelo Decreto n. ${ }^{\circ} 3.042$, de 28 de outubro de 1922, para exercer as suas atividades em Conceição do Arroio (antigo nome da cidade). Em 6 de junho de 1924, a escola, que já era denominada grupo escolar, passou a ser dirigida pela referida professora. Pelo Decreto $n .^{\circ} 3.588$, de 15 de janeiro de 
1926, a instituição foi elevada a colégio elementar, com a professora agora na função de diretora.

Pode-se dizer que a instalação de um estabelecimento de ensino em uma cidade do interior fez parte do movimento de incremento do ensino primário proposto pelo governo estadual. Embora o Partido Republicano Rio-Grandense estivesse vinculado ao positivismo e defendesse que as primeiras letras seriam atribuição da família, foi necessário, de acordo com Tambara (1995), adaptar-se às necessidades gaúchas, uma das quais a de oferecer o ensino primário por parte do poder público. Além disso, em âmbito nacional, o País vivenciava, de acordo com Nagle (2001), dois importantes movimentos educacionais: o entusiasmo pela educação e o otimismo pedagógico. Durante a Primeira República, via-se na educação a solução para os problemas nacionais. Além disso, tornava-se necessária a formação de cidadãos e diminuir o analfabetismo herdado do Império.

Ao realizar uma periodização da história da escola pública brasileira, Saviani (2004) define o ano de 1890 como marco inicial do que considera o "longo século XX". Para justificar tal escolha, o autor menciona vários fatores: economicamente, os cafeicultores estabeleceram-se; politicamente, a Monarquia encontrou o seu fim e instaurou-se a República; socialmente, já haviam surgido grupos sociais que começaram a pressionar a classe agroexportadora, como a classe média, os trabalhadores assalariados urbanos; a imigração já se havia estabelecido e havia ocorrido a abolição; culturalmente, o positivismo, o evolucionismo, o darwinismo, o romantismo encontravam-se na cena acadêmica.

Nesse turbulento contexto histórico, a escola ganhou um papel primordial na formação dos cidadãos da república nascente. Seja com o intuito de republicanizar, disciplinar e afirmar o regime ou com o objetivo de reduzir o analfabetismo que ainda atingia níveis altíssimos, a escola representava uma das principais ferramentas governistas, especialmente na figura do grupo escolar, com classes seriadas, e com um modelo de construção que levasse em conta interesses curriculares e pedagógicos. Adotado, acabou por tornar-se templo do saber, que não civilizava apenas os seus estudantes, mas também os habitantes da cidade. Isto ocorria porque seu prédio era, na 
maior parte das vezes, um diferencial em relação ao seu entorno. A arquitetura escolar passou a ter determinadas características que tornavam visível o poderio republicano.

Outra questão, não menos importante, que envolve a escola, foi citada por Hilsdorf (2005) e refere-se ao voto. Segundo a autora, a educação pelo voto e pela escola foi instituída pelos republicanos como grande arma da transformação evolutiva da sociedade brasileira, sendo oferecida em caução do progresso prometido pelo regime republicano. Dessa forma, a prática do voto pelos alfabetizados e a frequência à escola seriam responsáveis pela formação do homem progressista, adequado aos tempos modernos, transformando o súdito em cidadão ativo.

Tal transformação era essencial em um momento de transição entre dois regimes de governos distintos: a Monarquia, baseada na tradição e na hereditariedade, afirmando-se através de seus súditos, e a República, baseada no voto do alfabetizado e na participação do cidadão. Cabe aqui ressaltar que existe um caminho a ser traçado entre o súdito e o cidadão, cuja formação se dá através de instituições e símbolos. Logo, a República não se eximiu de transformar a cidade em palco de sua simbologia.

Era importante ser detentor de uma dessas ferramentas, pois, de acordo com Hilsdorf (2005), as forças políticas buscaram controlar as instituições educativas e seus agentes, com o objetivo de impor-lhes a forma escolar mais adequada e eficaz para administrar e conformar a sociedade. Neste mesmo sentido, Bencostta (2005) afirma que o discurso daqueles que implantaram o novo regime político em 1889 continha, além da justificação racional do poder, a fim de legitimar a República, o interesse em construir uma nação pautada em valores sintonizados com as mudanças que o mundo moderno apresentava. Logo, na tentativa de colocar-se contra as diversidades presentes no cotidiano social, Veiga (1998) afirma que a função do Estado foi a de assumir a liderança nos processos uniformizadores das populações, com o objetivo de adaptar as pessoas à sociedade em que vivem. Neste contexto, a escola tornou-se uma das instâncias legitimadoras do Estado, por sua função eminentemente ideológica.

A fundação do Grupo Escolar General Osório ocorreu justamente no contexto da Primeira República, como parte do esforço de difusão do ensino primário tanto em esfera 
estadual como nacional. Entretanto, a trajetória da instituição se prolongará por todo o restante do século XX e o início do século XXI.

Atualmente, a referida escola, ainda em funcionamento, conta com um acervo fotográfico de mais de 500 documentos, digitalizados em 2012. As imagens retratam vários tipos de atividades realizadas na instituição, bem como fotografias do prédio. Constam imagens de professores, alunos, exposições de trabalhos manuais, desfiles cívicos, comemorações, aulas de educação física, apresentações teatrais, entre outras. 0 estabelecimento conta com fotografias de todas as fases de sua história, desde a sua fundação até os dias atuais. Ressalta-se que a maior parte das fotografias é das décadas de 1980 e 1990, fato relacionado com o barateamento da produção fotográfica. Além disso, pode-se perceber uma diminuição das imagens impressas no século XXI, o que está relacionado com as fotografias digitais. O estabelecimento preserva, também, os decretos originais de sua fundação, que se encontram no mesmo arquivo.

\section{A pesquisa em acervos escolares e a cultura escolar}

A inserção da cultura escolar no âmbito da História da Educação Brasileira se deu há poucas décadas e a temática configurou-se em um dos objetos mais significativos em escala quantitativa nessa área. A abordagem do referido assunto atingiu grandes proporções, tendo em vista o número de trabalhos a ele dedicados. Deve-se ter em conta que o termo "cultura escolar" é de uma amplitude ímpar, pois abrange inúmeros objetos passíveis de análise pela História da Educação.

Foi especialmente a partir da década de 1990 que a cultura escolar começou a ser amplamente pesquisada em nível nacional. Faz-se mister mencionar os estudos de doutoramento de Souza (1996) e Faria Filho (1996). Nesse período, uma gama de trabalhos passou a figurar nas academias ${ }^{1}$. Em 1998, Faria Filho publicou, nos Cadernos de Pesquisa, da Fundação Carlos Chagas, um artigo intitulado "Cultura e práticas escolares:

\footnotetext{
${ }^{1}$ Deve-se ressaltar que a amplitude da temática cultura escolar dificulta a realização de um estado da arte mais completo, tendo em vista a pluralidade de assuntos inseridos nessa temática. Os estudos mencionados são resultado de uma pesquisa que considerou apenas os trabalhos em que consta o termo "cultura escolar" no título, no resumo ou nas palavras-chave.
} 
escrita, aluno e corporeidade". Nesse trabalho, o autor discutia algumas das implicações ao processo de produção/legitimação das diversas culturas escolares que acontecem no interior das instituições educacionais e nas práticas de escolarização dos corpos e de ensino-aprendizagem. O seu artigo visava a demonstrar que nas primeiras décadas do século XX, as práticas escolares, no Brasil, produziram o aluno no âmbito de um processo relacionado com a constituição de uma corporeidade escolar, ocorrido como pressuposto das relações pedagógicas. Faria Filho (1998) afirma que a reforma da instrução no estado de Minas Gerais representava os interesses da elite em fortalecer a República e vinculá-la à ideia de modernidade, em oposição ao atraso educacional herdado do período imperial.

Para atuar no sentido de fortalecer a memória e a identidade da Escola Estadual de Ensino Fundamental General Osório, seu acervo fotográfico, que conta com imagens de diversos momentos da história da instituição e que retratam elementos da cultura escolar, foi digitalizado e catalogado. Destaca-se que os acervos escolares contêm informações que possibilitam padronizar a análise dos diversos discursos e dos diferentes atores educativos. Entende-se que os acervos oferecem uma série de possibilidades de pesquisa, por se referirem a uma gama muito grande de temas relacionados à cultura escolar. Entretanto, uma vez mais, deve-se destacar o que a autora menciona sobre a necessidade de cruzar as fontes produzidas em âmbito institucional com fontes externas. Neste sentido, é importante ter em conta o que afirma Le Goff (2003) sobre a seleção dos documentos que chegaram até o presente.

É preciso também ressaltar que várias instituições não se preocupam com a manutenção de seus acervos históricos, tendo em vista as condições físicas pouco propícias para isso. Na Escola General Osório, ao contrário, há, atualmente, grande interesse em sua preservação. Acredita-se, porém, que alguns documentos se perderam ao longo da trajetória da instituição. O interesse atual constitui-se em um elemento facilitador para a realização de uma investigação na instituição, em consonância com o que aponta Vidal (2006) sobre o fato de, por meio do trabalho com acervos considerados mortos das instituições educacionais, os pesquisadores conseguirem mobilizar a comunidade escolar, como professores, alunos e funcionários. 


\section{A fotografia como importante elemento presente nos acervos escolares}

Com relação às fotografias, pode-se dizer que esta é insistentemente reconhecida como representação do real, não o real em si, tendo em vista a adequação de quatro para duas dimensões, de um mundo esférico e amplo para um formato retangular. Na imagem, o mundo ganha bordas, limites impostos pela tecnologia da reprodução fotográfica. Logo, fotografia configura-se em reprodução e representação. Reprodução, pois capta uma cena que é reproduzida; representação, porque tal cena é uma escolha e, dessa forma, relaciona-se a uma série de escolhas que levam ao seu resultado final.

Para tanto, deve-se levar em consideração o que afirma Fabris (1991), no sentido de que pensar a fotografia não implica apenas refletir sobre certo tipo de imagem ou sobre um sistema de trocas simbólicas. Tal reflexão requer bem mais, pois, desde o início, a fotografia demonstrou ser um agente de conformação da realidade em um processo de montagem e de seleção, no qual o mundo se revela "semelhante" e "diferente" ao mesmo tempo. A verossimilhança e as diferenças constituem características fundamentais do fazer fotográfico. Embora a convivência de tais traços possa, concomitantemente, parecer algo paradoxal, esta prática faz parte da essência da fotografia.

Destaca-se que fotografias impressas, ainda mais do que as originais, podem receber retoques. Desta forma, identificar a origem da fotografia é um dos pontos primordiais na sua análise. As fotografias integraram-se às fontes históricas somente em um período de "revolução documental", tendo em vista a primazia das fontes escritas em relação às fontes iconográficas. Ao mesmo tempo, a fotografia recebeu, por muito tempo, um tratamento de "espelho da realidade".

De acordo com Burke (2004): “[...] a expressão "câmera inocente”, cunhada na década de 1920, levanta um aspecto genuíno, embora a câmera tenha de ser empunhada por alguém e alguns fotógrafos sejam mais inocentes que outros" (p. 29). A partir do momento em que os historiadores definiram métodos para o tratamento e análise das imagens fotográficas, esta característica se perdeu. 
Um dos pontos críticos fundamentais no delineamento de metodologias para o embasamento da pesquisa com fontes iconográficas é a intencionalidade da imagem. Segundo Leite (1998, p. 72), à história, o que interessa na fotografia implica "o ângulo de quem observa, analisa e tenta compor fotografias já existentes. Não é uma prática para quem escolhe a imagem, nem para o fotógrafo". O entendimento que o observador tem da imagem é o campo da análise do historiador.

No entanto, para analisar a significação da imagem, é importante reconhecer que esta se encontra permeada de uma série de construções e intencionalidades, especialmente no que tange à sua produção. Fotografias nascem de necessidades e de interesses. A sua produção está condicionada a seleções e escolhas. São grupos sociais ou pessoas determinadas que as requerem.

Assim, conforme Dubois (1993), em toda reflexão sobre um meio qualquer de expressão deve-se colocar a questão fundamental da relação específica existente entre o referente externo e a mensagem produzida por esse meio. Trata-se da questão dos modos de representação do real ou, se preferirmos, da questão do realismo. Existe uma espécie de consenso de princípio que propõe que o verdadeiro documento fotográfico "presta contas do mundo com fidelidade". Foi-lhe atribuída uma credibilidade e esta virtude irredutível de testemunho baseia-se, principalmente, na consciência que se tem do processo mecânico de produção da imagem fotográfica, em seu modo específico de constituição e existência: o que se chamou de automatismo de sua gênese técnica. Segundo o autor, a foto é percebida como uma espécie de prova, ao mesmo tempo necessária e suficiente, que atesta indubitavelmente a existência daquilo que mostra.

Nesse mesmo sentido, Borges (2003) afirma que as imagens fotográficas devem ser vistas como documentos que informam a respeito da cultura material de um determinado período histórico, além de uma determinada cultura, e também como uma forma simbólica que atribui significados às representações e ao imaginário social. 0 trabalho com fotografias requer a contextualização baseada em outras fontes, o que permite perpetrar as concepções dos agentes implicados na criação do documento em questão. 
Ainda de acordo com a mesma autora (BORGES, 2003), longe de ser um documento neutro, a fotografia cria novas formas de documentar a vida em sociedade. Mais que a palavra escrita, o desenho ou a pintura, a pretensa objetividade da imagem fotográfica, veiculada nos jornais, não apenas informa o leitor - sobre datas, localização, nome de pessoas envolvidas nos acontecimentos, transformações do tempo curto -, como também cria verdades a partir de fantasias do imaginário, quase sempre produzidas por frações da classe dominante. A historiadora afirma:

A tese do realismo, da exatidão e da fidelidade das imagens fotográficas - traço atribuído à fotografia em seus primeiros anos - já não é mais cabível entre os anos 20 e 40 do século XX. Embora o Movimento Surrealista não possa ser responsabilizado pela mudança da caracterização da linguagem fotográfica, não há como negar que as montagens dos fotógrafos que dele participaram muito contribuíram para problematizar sua natureza. A partir de então, fica fortalecida a tese de que por detrás da chamada câmera lúcida há um ou mais indivíduos interessados em divulgar suas intenções sociais e suas visões da realidade. Mas nem por isso as imagens fotográficas perderam sua aura de magia e encanto. (BORGES, 2003, p. 72)

Ainda que a fotografia seja uma representa de elementos de realidade, é necessário lembrar que não só os fotógrafos manipulam as fotografias, como, em certa medida, os pesquisadores estabelecem o que deve ser visto. Para Burke (2004, p. 39), "no caso do testemunho de imagens, como em muitos outros casos, as testemunhas são mais confiáveis quando elas nos contam alguma coisa que elas, nesse caso os artistas, não sabem que sabem". O autor cita o exemplo de uma discussão conhecida na Inglaterra sobre o papel dos animais nos primeiros tempos da sociedade inglesa moderna. Keith Thomas observou, nos entalhes de David Loggan que retratam Cambridge no final do século XVII, que há cães por toda parte. Logo, o que o entalhador e os espectadores da época consideravam como algo comum tornou-se um assunto de interesse para historiadores culturais.

Deste modo, a imagem deixa transparecer algumas características que não se supunham presentes em sua superfície, especialmente da fotografia, por reproduzir cenas, construídas ou não; sendo assim, certos tipos de informação podem estar presentes sem ter passado pela minuciosa seleção de quem produziu a imagem. 
Retoma-se, então, a necessidade de uma metodologia de análise de fotografias. Para Flüsser (2002), o fator decisivo no deciframento das imagens é tratar-se de planos. $O$ significado da imagem encontra-se na superfície e pode ser captado num golpe de vista. No entanto, tal método de deciframento produzirá apenas um significado superficial. Quem quiser "aprofundar" o significado e restituir as dimensões abstraídas, deve permitir à sua vista vaguear pela superfície da imagem. Tal vaguear pela superfície é chamado de scanning. O traçado do scanning segue a estrutura da imagem, mas também os impulsos no íntimo do observador. O significado decifrado por este método será, pois, resultado de síntese entre duas "intencionalidades": a do emissor e a do receptor. Imagens oferecem aos seus receptores um espaço interpretativo: símbolos “conotativos”.

Para o autor, imagens são códigos que traduzem eventos em situações, processos em cenas, são mediações entre homem e mundo. Imagens têm o propósito de representar o mundo. Borges (2003) também é de opinião que, como outras imagens, a fotografia pressupõe um jogo de inclusão e exclusão, pois ela é escolha e, como tal, não apenas constitui uma representação do real, como integra um sistema simbólico pautado por códigos oriundos da cultura que os produz. Para a autora, diferentemente da pintura, do desenho, da caricatura, a representação fotográfica pressupõe uma inter-relação entre o olho do fotógrafo, a velocidade da máquina e o referente.

Ainda sobre a relevância da escolha na imagem fotográfica, afirma que, muitas vezes, enquanto os códigos culturais do fotógrafo definem a composição dos cenários fotográficos, a velocidade da câmera pode captar fragmentos do real, não previstos na idealização das poses, porque a chapa fotossensível capta a luz emanada do objeto fotografado sem a intervenção humana. A fotografia, nessa e apenas nessa fração de tempo, é uma mensagem sem código; entretanto, quando a intromissão de fragmentos do real interfere no planejamento da pose, o fotógrafo sente-se livre para cortar, selecionar, fazer e refazer seu quadro. Para Borges:

A imagem fotográfica conjuga realidade e ficção. Os planos, os focos, o jogo de sombra e luz que a compõem são marcados pela encenação que a intenção do fotógrafo cria. O produto fotográfico oscila entre aquilo que escapa e isto que nela infiltra. (BORGES, 2003, p.84) 
As múltiplas dimensões de significados que orientam a interpretação da imagem dependem da reconstrução do sistema cultural, do contexto em que o ato fotográfico ocorreu e das identidades dos sujeitos envolvidos naquele evento. Em se desconsiderando a análise do contexto original de sua criação, seu alcance fica restrito aos índices incompletos da realidade apresentados pela imagem. Ao preservar um instante no tempo, a imagem aponta para uma memória que é intrínseca a ela própria, mas envolve, também, uma memória externa, a memória do espectador.

Além disso, deve-se ter em conta que se utilizam imagens impressas, cuja análise, como mencionado anteriormente, deve ser encarada de forma diferente das fotografias originais. Nesse ponto, ressaltam-se o papel da imprensa e as suas formas de reprodução. A imprensa constituiu um meio de comunicação formador de opiniões, utilizando-se das imagens para dar mais "credibilidade aos fatos", expressão comumente utilizada quando se aborda o tema imprensa. Ao mesmo tempo em que ela forma opiniões, produz formatos determinados de textos e imagens. De acordo com Burke (2004, p.21), "as consequências da imprensa têm comumente sido discutidas em termos da padronização e da fixação de textos em forma permanente, e pontos semelhantes podem ser levantados sobre imagens impressas". As fontes utilizadas neste estudo encontram-se inseridas em um conjunto de representações que respondem a um determinado formato, mais específico, ainda, por tratar-se de fotografias e textos produzidos durante a Primeira República. É possível afirmar que os textos e as imagens ganham formatações distintas conforme a época e a forma de comunicação mais adequada para chegar ao público-alvo.

Para possibilitar a análise das fontes digitalizadas até o presente momento, as fotografias foram arroladas em planilhas (Fig. 1), nas quais receberam uma identificação composta por letras e números. A primeira parte dessa identificação é composta pela identificação do arquivo a que se refere - Arquivo Fotográfico da Escola Estadual General Osório, ou Afeego. É preciso destacar que a importância de mencionar a origem se deve ao fato de que, concomitantemente, se realiza uma investigação no Arquivo Histórico Antonio Stenzel Filho, no qual várias imagens e documentos sobre a instituição estão sendo digitalizados ou transcritos, e catalogados. Depois da referência ao acervo, a identificação apresenta a década em que a imagem foi produzida, seguida do número da 
imagem na totalidade do corpo documental. Dessa forma, a identificação das fotografias constitui-se da seguinte forma: Afeego (1920)-001.

Tendo em vista que $60 \%$ das fotografias catalogadas anteriormente contavam com legendas nas quais se identificava ao menos o ano em que haviam sido tiradas, optou-se por definir um campo para a data. É preciso considerar que das imagens com identificação de data na legenda se conta com duas da década de 1930, quatro da década de 1960, oito da década de 1970, vinte e três da década de 1980, cento e vinte da década de 1990 e sessenta produzidas a partir do ano 2000. As planilhas contam, também, com campos específicos para legenda, personagens, temática e palavras-chave. Atualmente, realizou-se uma indexação dos termos utilizados no último campo citado, pretendendo-se realizar o mesmo com o campo temática.

Figura 1 - Planilha com a identificação do acervo fotográfico da Escola Estadual General Osório

\begin{tabular}{|c|c|c|c|c|c|}
\hline Identificacão/Númerd & Data & Legenda & Personagens & Temática & Palavras-chave \\
\hline AFEEGO(1920) - 001 & - & Turma de Alunos da década de 20 & - & Confraternização de alunos & Discentes - Alunos \\
\hline AFEEGO(1920) - 002 & - & Desfile da semana da pátria & - & Participação do desfile cívico & Comemorą̧ẵo escolar - Desfile cívico - 7 de setembro \\
\hline AFEEGO(1920) - 003 & - & 7 de Setembro & - & Participação do desfile cívico & Comemoraçãoo esoolar - Desfile oívico - 7 de setembro \\
\hline AFEEGO(1920) - 004 & $\cdot$ & Aula de educação física & $\cdot$ & Aula de Educação Física & Atividade escolar - Em aula \\
\hline AFEEGO(1920) - 005 & - & Sala dos professores & - & $\begin{array}{l}\text { Confraternização entre professoras na sala } \\
\text { dos professores }\end{array}$ & Servidores - Professores \\
\hline AFEEGO(1920) - 006 & - & Intervalo & - & Confraternização de alunos na hora do interva & Discentes - Alunos \\
\hline AFEEGO(1920) - 007 & - & Alunos de diversas turmas & - & & Discentes - Alunos \\
\hline AFEEGO(1920/30) - 008 & - & Amostra de trabalhos no final do ano & - & Amostra de trabalhos escolares & Atividade escolar - Exposição de trabalho(s) \\
\hline AFEEGO(1920/30) - 009 & - & Reunião com os alunos & Profe Maria Santos e alunos & Professora Maria Santos em reunião com alun & Atividade escolar - Reunião entre discentes e docentes \\
\hline AFEEGO(1920/30) - 010 & $\cdot$ & 7 de Setembro & $\cdot$ & Participação do desfile cívico & Comemoraçăo escolar - Desfile cívico - 7 de setembro \\
\hline AFEEGO(1920/30) - 011 & $\cdot$ & 7 de Setembro & - & Participação do desfile cívico & Comemorą̧ẵo escolar - Desfile cívico - 7 de setembro \\
\hline AFEEGO(1930) - 012 & - & $\begin{array}{l}\text { Passagem da escola pelo palanque } \\
\text { oficial em } 7 \text { de setembro }\end{array}$ & - & Participação do desfile cívico & Comemoraçấo escolar - Desfile cívico - 7 de setembro \\
\hline AFEEGO(1930) - 013 & - & $\begin{array}{l}\text { Passagem da escola pelo palanque } \\
\text { oficial em } 7 \text { de setembro }\end{array}$ & - & Participação do desfile cívico & Comemoraçăo esoolar - Desfile cívico - 7 de setembro \\
\hline AFEEGO(1930) - 014 & - & $\begin{array}{l}\text { Passagem da escola pelo palanque } \\
\text { oficial em } 7 \text { de setembro }\end{array}$ & ( & Participação do desfile cívico & Comemoraçãoe escolar - Desfile cívico - 7 de setembro \\
\hline AFEEGO(1930) - 015 & - & Fim de ano - Sala dos Professores & \begin{tabular}{|l|} 
Clélia Silveira, Isaura, Helena \\
Camargo, M Souza, Norma, Aydil e \\
Dinah
\end{tabular} & $\begin{array}{l}\text { Confraternição entre professoras na sala dos } \\
\text { professores }\end{array}$ & Servidores - Professores \\
\hline AFEEGO(1930) - 016 & 1939 & Comemoração do Natal & - & Comemoração festiva do Natal & Comemoração escolar - Festa religiosa \\
\hline AFEEGO(1930) - 017 & $\cdot$ & Professora Maria Rita com seus alunos & - & Professora e seus alunos & Discentes e docente(s) em espaço escolar \\
\hline AFEEGO(1930) - 018 & - & 7 de Setembro & - & Participação do desfile cívico & Comemorą̧ăo escolar - Desfile cívico - 7 de setembro \\
\hline AFEEGO(1930) - 019 & 1936 & Professoras Lyra e Clélia e seus alunos & - & $\begin{array}{l}\text { Professora Lyra e Professora Cléia reunidas } \\
\text { com seus alunos }\end{array}$ & Discentes e docente(s) em espaço escolar \\
\hline
\end{tabular}

Fonte: Projeto História das instituições educacionais e seus acervos escolares na cidade de Osório - RS

Atualmente, realizou-se uma indexação dos termos utilizados no campo palavraschave (Fig. 2), pretendendo-se realizar o mesmo com o campo temática. Foram identificados os termos mais recorrentes naquele item; posteriormente, procurou-se estabelecer terminologias que abarcassem, de forma geral, todos os temas recorrentes nas fotografias constantes no acervo fotográfico da Escola General Osório. As palavras- 
chave foram organizadas em: atividade escolar, comemoração escolar, discentes e docente(s) em espaço escolar, feira do livro, prédio escolar e recordação escolar. Estes termos foram subdivididos em outros ainda mais específicos.

Figura 2 - Indexação dos termos constantes no item "palavras-chave"

\begin{tabular}{|c|c|c|c|c|c|}
\hline A & C & D & $\mathbf{F}$ & $\mathbf{P}$ & $\mathbf{R}$ \\
\hline Atividade Escolar & Comemoração Escolar & Discentes e docente(s) em espaço escolar & Feira do Livro & Prédio Escolar & Recordação Escolar \\
\hline - Atividade lúdica & - Aniversário da escola & Discentes & & - Construção & \\
\hline - Em aula & • Chá & - Alunos & & - Fachada & \\
\hline - Exposição de trabalho(s) & - Confraternização & - Grêmio Estudantil & & - Higienização & \\
\hline - Apresentação artística & Início do ano letivo & Servidores & & - Interior & \\
\hline -Banda & - Desfile cívico & - Atividades entre servidores & & - Reforma & \\
\hline - Coral & -7 de setembro & - Equipe Diretiva & & & \\
\hline - Grupo de dança & -20 de setembro & -Ex-diretores & & & \\
\hline -Piano & - Festa de Dia das Crianças & - Professores & & & \\
\hline - Escaleta & - Festa de Dia das Mães & & & & \\
\hline - Teatro & - Festa de Dia dos Pais & & & & \\
\hline - Lideranças mirins & - Festa de Dia dos Professores & & & & \\
\hline - Prática esportiva & - Festa junina & & & & \\
\hline - Reunião entre discentes e docentes & - Festa religiosa & & & & \\
\hline - Vídeo & -Igreja da Matriz & & & & \\
\hline - Visita técnica & - Formatura & & & & \\
\hline - Centro cívico & - Inauguraçốes & & & & \\
\hline Atividade Filantrópica & & & & & \\
\hline
\end{tabular}

Fonte: Projeto História das instituições educacionais e seus acervos escolares na cidade de Osório - RS

Assim, as palavras-chave iniciam-se por um termo abrangente e seguem-se com termos mais específicos, o que visa a facilitar o acesso de pesquisadores que desejem acessar o acervo fotográfico da referida instituição.

\section{Os documentos escritos e a imprensa}

As fontes escritas (documentos e jornais utilizados) da mesma maneira que as iconográficas, também foram arroladas em planilhas. Com relação aos últimos, foram identificados o nome do periódico, o título da notícia, a data, o autor e a temática.

Deve-se ter em conta que a imprensa é uma fonte inestimável de pesquisa para os historiadores da educação, tendo em vista seu papel de difusor, formador de informações, opiniões e ideologias. Era tamanha a importância da mídia impressa que no Brasil Colonial ela não era produzida. De acordo com Lustosa (2004), até 1808, data da 
chegada de d. João VI, as letras impressas eram proibidas no Brasil. Além disso, as poucas tentativas de estabelecimento de tipografias esbarraram na intransigência das autoridades portuguesas, as quais consideravam perigosa a existência de jornais.

Houve certa relutância na utilização da imprensa como fonte histórica, embora a sua importância fosse reconhecida. Os fatores que explicam tal situação encontram-se na tradição, dominante durante o século XIX e nas décadas iniciais do século XX, na busca da verdade dos fatos, encontrada por intermédio de documentos oficiais. Nesse contexto, os jornais pareciam pouco adequados para a recuperação do passado, já que se constituíam em "enciclopédias do cotidiano", contendo registros fragmentários do presente, realizados sob o influxo de interesses, compromissos e paixões. No entanto, segundo a autora, "o estatuto da imprensa sofreu deslocamento fundamental ainda na década de 1970: ao lado da história da imprensa e por meio da imprensa, o próprio jornal tornou-se objeto da pesquisa histórica" (LUCA, 2005, p. 118).

A utilização dos periódicos como fonte de pesquisa permite a análise de discursos e ideologias, de características da vida cotidiana, entre tantas outras informações passíveis de serem extraídas da imprensa. Para Carvalho, Araújo e Gonçalves Neto:

Entendemos que a imprensa, ligada à educação, constitui-se em um
"corpus documental” de inúmeras dimensões, pois consolida-se como
testemunho de métodos e concepções pedagógicos de um determinado
período. Como também da própria ideologia moral, política e social,
possibilitando aos historiadores da educação análises mais ricas a
respeito dos discursos educacionais, revelando-nos, ainda, em que
medida eles eram recebidos e debatidos na esfera pública, ou seja, qual
era a sua ressonância no contexto social. (CARVALHO; ARAUJO;
CONÇALVES NETO, 2002, p. 72)

Nos estudos históricos, a imprensa mostra-se como um instrumento de pesquisa relevante, pois em suas páginas é que se divulgam e consolidam as principais representações sociais (GONÇALVES NETO, 2002), ao mesmo tempo em que se cria um espaço público através do seu discurso - social e simbólico (BASTOS, 2002). Logo, os jornais, muito longe de sua pretensa imparcialidade, são capazes de formar opiniões, disciplinar. 
Pode-se dizer que os periódicos têm sido uma fonte muito útil para a coleta de dados, possibilitando a leitura das manifestações contemporâneas aos acontecimentos. Dessa forma, como já foi dito, devemos ter em conta que os documentos não são textos inocentes e transparentes, mas escritos por pessoas com diferentes intenções e estratégias. Para Lopes e Galvão (2005), “no trabalho com o material escrito, mas não só, é preciso levar em conta tanto os silêncios dos documentos quanto a sua ausência" (p. 92). Além disso, segundo Le Goff:

O documento não é qualquer coisa que fica por conta do passado, é um produto da sociedade que o fabricou segundo as relações de forças que aí detinham o poder. Só a análise do documento enquanto monumento permite à memória coletiva recuperá-lo e ao historiador usá-lo cientificamente, isto é, com pleno conhecimento de causa. (LE GOFF, 2003,p. 545)

Com relação à História da Educação nos jornais, Nóvoa, Teixeira e Bandeira (2002) afirmam que a imprensa revela as múltiplas facetas dos processos educativos, em uma perspectiva interna ao sistema de ensino (cursos, programas, currículos, etc.) e também no que diz respeito ao papel desempenhado pelas famílias e pelas diversas instâncias de socialização das crianças e dos jovens. Dessa forma, é admissível dizer que a imprensa propicia o contato com uma série de informações, as quais, organizadas de forma adequada, constituem uma rica fonte de pesquisa.

No entanto, ao propor-se a análise dos referidos textos, é importante dizer que todo tipo de fonte deve passar por uma crítica com a finalidade de se desvelar o emaranhado de ideologias que as permeiam. A presente pesquisa utiliza jornais como fonte. Deve-se ter em conta que se optou por abordar o periódico como documento, no sentido proposto por Le Goff. Para este autor, “o documento é monumento. Resulta do esforço das sociedades históricas para impor ao futuro - voluntária ou involuntariamente - determinada imagem de si próprias" (LE GOFF, 2003, p. 548). Dessa maneira, deve-se tomar a imprensa como veiculadora de interesses sociais e recusar a ideia de que seja apenas uma difusora de informações, questionando a sua imparcialidade e neutralidade. Esta última palavra não pode ser relacionada às fontes históricas de pesquisa. Tendo em vista as características anteriormente citadas, ao utilizar-se a imprensa como fonte, é preciso seguir determinada metodologia: 
Cabe ao historiador promover uma aglutinação dos fatos que ele localiza, procurando retirar desse seu caleidoscópio uma dada racionalidade, visando a identificar, na medida do possível, as diferentes histórias que compõem o todo histórico, com o objetivo de construir uma história menos excludente. Nesta perspectiva, percebe-se que a imprensa se transformou em objeto de referência para apreensão e compreensão do processo histórico-educacional. (CARVALHO, ARAUJO; GONÇALVES NETO, 2002, p. 74)

Além disso, como afirma Bastos (2002):

“[...] Cabe ao pesquisador fazer uma desmontagem do texto - da imprensa - a fim de desvelar os significados, as contradições e as diferenças de forma e de conteúdo das falas que produz. Essa desmontagem significa análise do processo e das condições de sua produção/construção, a partir dos discursos disponíveis [...]”. (BASTOS, 2002, p.153)

O pesquisador deve conhecer a sua fonte de forma a conseguir realizar a desconstrução do texto e analisar o processo e as condições de produção. Foi dessa forma que se buscou conhecer os periódicos em circulação, percebendo quais eram as suas vinculações partidárias e doutrinárias, de forma a desvelar os interesses que se encontravam por trás de suas notícias.

\section{Considerações finais}

O presente estudo, como já mencionado, refere-se a um projeto de pesquisa em andamento. Deve-se, porém, destacar a importância de atuar no sentido de preservar os acervos escolares em cidades do interior, caso da cidade de Osório, no Rio Grande do Sul. A manutenção dos documentos até hoje se deu com base no interesse de alguns profissionais que trabalham na instituição, notadamente à professora Rosângela.

Porém, por não existir uma política de preservação dos acervos escolares, esses poderiam não ter chegado aos diais atuais.

Conforme já se disse, a pesquisa em acervos educacionais permite o estudo de uma série de elementos que constituem a cultura escolar. A Escola General Osório inclui, em seu acervo, fotografias de estudantes, professores, comemorações, aulas de 
educação física, entre outros, a partir da década de 1920. Ressalte-se a riqueza de sua documentação no que tange às possibilidades de temas e períodos a serem estudados. No ano de 2013, o projeto deu continuidade ao trabalho iniciado em 2012, por meio da organização do material coletado. Além disso, iniciou-se uma pesquisa em fontes escritas, notadamente em periódicos.

Entre as perspectivas futuras para o prosseguimento do projeto em 2014, encontra-se o acondicionamento do acervo, a datação das imagens, a identificação dos personagens. Objetiva-se, ainda, traçar comparações entre o acervo e as fontes documentais encontradas, identificar e analisar práticas realizadas na instituição em diferentes períodos, especialmente no que tange às representações da infância, às práticas religiosas em ambiente laico e às vestimentas das professoras e sua representação social. 


\section{Referências}

BASTOS, Maria Helena Câmara. Espelho de papel: a imprensa e a história da educação. In: ARAÚJO, José Carlos Souza; GATTI JR., Décio. (Orgs). Novos temas em história da educação brasileira: instituições escolares e educação na imprensa. Campinas: Autores Associados; Uberlândia, MG: EDUFU, 2002, p.151-174.

BENCOSTTA, Marcus Levy Albino. História da Educação, arquitetura e espaço escolar. São Paulo: Cortez, 2005.

BORGES, Maria Eliza Linhares. História \& fotografia. Belo Horizonte: Autêntica, 2003.

BURKE, Peter. Testemunha ocular: história e imagem. Bauru, SP: EDUSC, 2004.

CARVALHO, Carlos Henrique de; GONÇALVES NETO, Wenceslau. Imprensa e Pensamento Pedagógico na República Velha (Uberabinha-MG 1907 - 1922). In: CONGRESSO BRASILEIRO DE HISTÓRIA DA EDUCAÇÃO, II, Natal, 2002. Anais do II Congresso Brasileiro de História da Educação. Natal: Editora da UFRN, 2002.

CARVALHO, Carlos Henrique de; ARAUJO, José Carlos Souza; GONÇALVES NETO, Wenceslau. Discutindo a história da educação: a imprensa enquanto objeto de análise histórica (Uberlândia-MG, 1930-1950). In: ARAÚJO, J. C. S.; GATTI JR., D. (Orgs.). Novos temas em história da educação brasileira: instituições escolares e educação na imprensa. Campinas: Autores Associados; Uberlândia, MG: EDUFU, 2002, p.67-89.

DUBOIS, Philippe. O ato fotográfico e outros ensaios. Campinas, SP: Papirus, 1993.

FABRIS, Annateresa (Org.). Fotografia usos e funções no século XIX. São Paulo: Editora da Universidade de São Paulo, 1991.

FARIA FILHO, Luciano Mendes de. Dos Pardieiros aos Palácios: forma e cultura escolares em Belo Horizonte. São Paulo: USP, 1996.

FLUSSER, Vilém. Filosofia da caixa preta: ensaio para uma futura filosofia da fotografia. Rio de Janeiro: Relume Dumará, 2002 - (Conexões; 14).

FRAGO, Antonio Viñao. Do espaço escolar e da escola como lugar: propostas e questões. In:____ ESCOLANO, Agustín. Currículo, espaço e subjetividade: a arquitetura como programa. 2. ed. - Rio de Janeiro: DP\&A, 2001, p.59-136. 
FRAGO, Antonio Viñao. Tiempos Familiares, Tiempos Escolares (Trabajo Infantil y Asistencia Escolar en España durante la segunda mitad Del Siglo XIX y El primer tercio del XX). Revista de História da Educação, ASPHE, v.9, n.17, p.33-50, 2005.

FRAGO, Antonio Viñao. A história das disciplinas escolares. Revista Brasileira de História da Educação, n.18, set./dez., p.173-216. 2008.

GONÇALVES NETO, Wenceslau. Imprensa, civilização e educação: Uberabinha (MG) no início do século XX. In: ARAÚJO, J. C. S.; GATTI JR., D. (Orgs.). Novos temas em história da educação brasileira: instituições escolares e educação na imprensa. Campinas Autores Associados; Uberlândia, MG: EDUFU, 2002, p.197-225.

HILSDORF, Maria Lucia Spedo. História da Educação Brasileira: Leituras. São Paulo: Pioneira Thomson Learning, 2005.LE GOFF, Jacques. História e memória. Campinas: Editora da UNICAMP, 2003.

LEITE, Mirian Moreira. Retratos de família. São Paulo: Editora da Universidade de São Paulo, 1993.

LEITE, Mirian Moreira. Texto Visual e Texto Verbal. In: FELDMAN-BIANCO, Bela; LEITE, Mirian L. Moreira (Orgs.). Desafios da imagem: fotografia, iconografia e vídeo nas ciências sociais. Campinas: Papirus, 1998.

LOPES, Eliane Marta Teixeira; GALVÃO, Ana Maria de Oliveira. História da educação. Rio de Janeiro: DP\&A, 2005, 2. ed.

LUCA, Tânia Regina de. História dos, nos e por meio dos periódicos. In: PINSKY, Carla Bassanezi (Org.). Fontes históricas. São Paulo: Contexto, 2005.

LUSTOSA, Isabel. O nascimento da imprensa brasileira. 2. ed. Rio de Janeiro: Jorge Zahar Ed., 2004 (Descobrindo o Brasil).

NAGLE, Jorge. Educação e Sociedade na Primeira República. - 2.ed. - Rio de Janeiro: DP\&A, 2001.NÓVOA, António; BANDEIRA, Filomena; PAULO, João Carlos; TEIXEIRA, Vera. A Imprensa de Educação e Ensino: concepção e organização do repertório português. In: CATINAI, Denice Bárbara; BASTOS, Maria Helena Câmara. In: Educação em Revista: A Imprensa Periódica e a História da Educação. - São Paulo: Escrituras Editora, 2002, p.11-32.

SAVIANI, Demerval. O Legado Educacional do “Longo Século XX” Brasileiro. In: SAVIANI, Demerval. O Legado Educacional do século XX no Brasil. Campinas, SP: Autores Associados, 2004, p.9-58. 
SOUZA, Rosa Fátima. Templos de Civilização: Um Estudo sobre a Implantação dos Grupos Escolares no Estado de São Paulo. São Paulo: USP, 1996.

TAMBARA, Elomar. Positivismo e Educação: a educação no Rio Grande do Sul sob o Castilhismo. Pelotas: Ed. Universitária/UFPel, 1995.

VEIGA, Cynthia Greive. Cidade e Educação, modernidade e modernismo. In: SOUZA, Cynthia Pereira; CATANI, Denice Barbara (Orgs.). Práticas Educativas Culturas Escolares Profissão Docente. São Paulo: Escrituras Editora, 1998, p.171-180.

VIDAL, Diana Gonçalves (Org.). Grupos Escolares: cultura escolar primária e escolarização da infância no Brasil (1893 - 1971). Campinhas: Mercado de Letras, 2006.

Recebido em: 27/11/2013 Aprovado em: 12/02/2014

Universidade do Estado de Santa Catarina - UDESC Programa de Pós-Graduação em Educação - PPGE Revista Linhas Volume 15 - Número 28 - Ano 2014 revistalinhas@gmail.com 